\title{
Space scientists protest at decision to scrap plans for Pluto mission
}

Washington. Daniel Goldin, administrator of the US National Aeronautics and Space Administration (NASA), has decided to scrap plans for a spacecraft mission to Pluto, claiming they are too expensive. His decision has not only sent frustrated project designers back to the drawing board but also casts doubt on NASA's willingness to mount any expedition to the last uncharted planet in the near-term future.

Goldin told last week's meeting of the American Astronomical Society's Division for Planetary Science (DPS) in Washington that $\$ 600$ million was "way, way too much for one mission". Later in the meeting, William Piotrowski, head of NASA's Solar System exploration division, told a workshop that "the current concept for the Pluto mission is dead".

The decision is a major blow to scientists and engineers who have been working on plans for the Pluto Fast Fly-By (PFF), as they have consistently met cost and performance targets set by Goldin. Indeed, it was partly Goldin's own interest in the Pluto concept that elevated it within the pecking order of proposed NASA planetary missions two years ago (see Nature 358, 701; 1992). The mission had been targeted for a "new start" in NASA's 1998 budget.

The PFF concept, which Goldin has touted as a showpiece for his "better, cheaper, faster" philosophy, called for sending two identical spacecraft on a fast, direct route to the planet, with a launch in 2001 and arrival at Pluto in 2008. Mission designers relied heavily on advanced technology, much of it still being developed, to reduce the spacecraft's weight and boost performance.

They also stripped the science payload down to a $7-\mathrm{kg}$ package with only four science instruments. The PFF would have been lighter and more capable than the Clementine spacecraft that mapped the Moon earlier this year and would have used twothirds the number of people for mission operations during the Pluto encounter.

More than a year ago, Goldin assured PFF team members that if they brought their costs under $\$ 750$ million, he would back the project. He also encouraged them to solicit

\section{Economist tipped as German research minister}

Munich. Klaus Töpfer, Germany's environment minister for the past seven years and formerly a professor of economics, is being tipped to become Germany's next research minister when the new cabinet is announced at the end of this month.

Töpfer, who is 56, is a Christian Democrat whose party managed to hold on to
Russian participation. The team met both targets by trimming the mission's price to $\$ 580$ million, including a launch on a Russian Proton rocket and a small Russian probe dropped into Pluto's atmosphere.

The project also received high marks from an independent review team recruited

\section{IMAGE UNAVAILABLE FOR COPYRIGHT REASONS}

Little Brother: The small size of the Pluto spacecraft (right), compared here to the Cassini spacecraft, has challenged the ingenuity of NASA engineers.

by Goldin from the same Pentagon organization that funded Clementine. But Goldin is now saying that this is not sufficient. As science, admitted at last week's DPS meeting, "the goalposts have moved".

The decision has raised questions about Goldin's mercurial management style. Some admire it, saying it stimulates innovation and efficiency; others find it disruptive. Goldin defends his decision by explaining that NASA has less money now than two years ago, when he first became excited about the project. "I want to keep the heat on to get the cost down," he says.

The agency also has higher priorities in planetary science, starting with a new line of low-cost Discovery missions expected to begin in 1996 (winners will be chosen in January from among 28 proposals). In addition, NASA science managers recently added a new \$120-million project to their wish list, namely participation in the European Rosetta

power in last month's general election. If his appointment is confirmed, Töpfer could inherit broader responsibilities than his predecessor Paul Krüger, an east German, as the federal research and education ministries may be merged into what is being informally called a "ministry of the future". Wesley Huntress, NASA's head of space comet mission, set for launch in 2003. This would partly make up for a NASA comet rendezvous mission cancelled by Congress two years ago.

The PFF project suffers from not having as large a constituency as these other missions. Pluto was not listed as a priority in a recent report by the National Research Council's Committee on Planetary and Lunar Exploration (COMPLEX), which recommended focusing on comets, Mars, Jupiter and a search for planets around other stars instead. But NASA's scientific advisory committees have supported the Pluto mission, as have the agency's senior science managers. The idea has also gained support from the press and public.

Goldin told his audience at DPS that he sympathized with those at the NASA Jet Propulsion Laboratory (JPL) who were keen to get the Pluto mission started, adding "I don't want them to feel it's over". Huntress, too, advises patience, and says he believes some kind of Pluto mission will be approved eventually, perhaps even in time for a 2001 launch - but the PFF team has been told that study money for such a mission is being cut.

Cutting the cost to $\$ 250$ million, which appears to be Goldin's target, is a "very tall order", says Alan Stern of the Southwest Research Institute in San Antonio, Texas, who led the NASA advisory group that shaped the objectives for the PFF mission.

Stern points out that when mission reserves and other built-in costs are deducted from the $\$ 580$ bill, it leaves only $\$ 390$ million for two spacecraft - including the launch - roughly equivalent to the price of two $\$ 150$ million Discovery missions, which do not include launch.

Richard Terrile, PFF's project scientist at JPL, says the cost could be trimmed to between $\$ 300$ million and $\$ 380$ million if NASA settled for sending only one spacecraft (outside advisory groups have advised against that strategy as too risky), and took a slower route using a gravity boost from Jupiter. He is sceptical that the price can come down much lower.

Members of the PFF team say they are less bothered by the cost-cutting than by the uncertainty about what Goldin wants. Although he has admonished space engineers to save money by using "revolutionary technology" for the Pluto mission, he has not spelled out what that means. "They [NASA] want to fly something that's higher-tech [than PFF]," said Terrile at the DPS Pluto workshop, "even though nothing flying on this mission has ever been flown before."

Tony Reichhardt 